who must be kept fully informed about matters relating to their patients' care. Consultant psychiatrists retain the ultimate responsibility for all aspects of medical care of an in-patient under their care, including discharge. This includes ensuring that effective on-call arrangements are in place for medical cover, including the prompt availability of a consultant at all times, at least for consultation by telephone. Consultants must ensure that there is appropriate staffing at all times for the unit concerned to ensure safe delivery of patient services, taking into account local variations with respect to the siting of units. Appropriate medical staff must be available at all times in any environment where acutely ill psychiatric patients are treated. It may be necessary for inadequacies in medical cover to be brought to the attention of the managers who are responsible.

Consultants should collaborate in ensuring that comprehensive mental health services are provided by cooperating agencies with clear responsibilities. Community services should be coterminous, so that social services, psychiatric services and GPs can function together. Clear lines of clinical and medical responsibility for patients referred from the community to secondary care services must be carefully maintained; it is desirable that all such patients should be under the care of a named consultant psychiatrist.

The Royal College of Psychiatrists' publication Caring for a Community offers comprehensive guidance on community psychiatric care and how best to maintain standards of good practice. This builds on recommendations made in the care programme approach, which was produced to provide a framework for the care in England of mentally ill people outside hospital. The essential elements are:

- systematic assessment of health and social care needs;

- an agreed care plan

- allocation of a key worker;

- regular review of the patient's progress.

The medical care of out-patients remains the on-going responsibility of GPs, with consultants acting in an advisory capacity or providing specialised treatment.

A copy of this paper is posted on the College website at http://www. rcpsych.ac.uk/members/membership/ workOverload.htm

\section{The Royal College of Psychiatrists Winter Business Meeting}

27 January 2004, 4.30 p.m., to be held at the Royal College of Psychiatrists following the meeting of Council. Chaired by the President, Dr Mike Shooter

\section{Agenda}

1. To approve the Minutes of the previous Winter Business Meeting, held at the Royal College of Psychiatrists on 28 April 2003

2. Obituary

3. Election of Honorary Fellows

\section{HRH The Princes Royal}

Her Royal Highness is the seventh holder of the title, The Princess Royal. In 1987, The Princess Royal was made a Fellow of the Royal Society and in 1994, The Queen appointed her a Knight of the Most Noble Order of the Garter. In 2000, to mark her 50th birthday, The Princess Royal was appointed to the order of the Thistle in recognition of her work for charities.

The Save the Children Fund, of which she has been President since 1970, was the first major charity with which she became closely associated, and it has given her great insight into the needs of children worldwide. This association, and her love of equestrian sports, have been the starting point for the development of a very wide range of charitable appointments, to all of which she devotes a large part of her working life. The Princess was also closely involved with the creation of some charities, notably The Princess Royal's Trust for Carers, Transaid and Riders for Health. She also serves as President of the Register of Engineers for Disaster Relief. She succeeded her late grandmother, Her Majesty Queen Elizabeth The Queen Mother, as Chancellor of London University in 1981.

The Princess Royal is President or Patron of some 222 organisations, including:

\section{Riding for the Disabled}

Royal College of Anaesthetists Royal College of Midwives

Royal College of Paediatrics and Child Health Save the Children

The Princess Royal Trust for Carers The Queen Victoria Hospital NHS Trust

In addition to working for her many charities and regiments, both at home and overseas, the Princess carries out up to three overseas tours each year for the Foreign and Commonwealth Office in support of British interests. She also carries out a very wide range of official duties and visits in the United Kingdom in support of regional authorities and local institutions.

From her early days, riding was the Princess's great passion, and she soon proved herself an expert horsewoman She regularly took part in the Horse of the Year Show at Wembley and the Badminton Horse Trials. In September 1971, she won the individual European 3 Day Event at Burghley, and was nominated Sportswoman of the Year by the Sports Writers' Association, the Daily Express newspaper and World Sport (the journal of the British Olympic Association). She was also voted the BBC Sports Personality of 1971

In 1973, The Princess was a member of the British team in the European 3-Day Event Championships at Kiev in the Soviet Union. Two years later, in the same contest in Germany, she won silver medals as an individual competitor and as a team member. The Princess also competed in the 1976 Montreal Olympic Games as a member of the British 3-Day Event team. This led in 1983 to her becoming President of the British Olympic Association. In 1988, she became one of the two UK members of the International Olympic Committee. The Princess has been an enthusiastic supporter of the British Olympic teams at successive games since 1983 , including the highly-successful games in Sydney in 2000.

For her life-long support of many charities and organisations in the area of health, The Princess Royal is highly commended for the Honorary Fellowship, and her acceptance would be an honour for the College.

\section{The Lord Bragg}

The work of Melvyn Bragg, FRSL, DLitt MA, FRTS, television presenter, novelist and broadcaster, and currently President of MIND, will be very familiar to most people. Lord Bragg's name is synonymous with the arts in general. Lord Bragg has worked in broadcasting since 1961 and is currently Controller of Arts and Features at LWT, Editor and Presenter of the South Bank Show and Executive Producer of several other Arts strands. He also writes for numerous publications. He is President of the National Campaign for the Arts, a Governor of the LSE and Chancellor of Leeds University. He was made a Life Peer in 1998. In 2001, he won the Prix Italia Special Award for 25 seasons of The South Bank Show and, among many other achievements, has received numerous Honorary Doctorates and Fellowships from academic organisations.

Lord Bragg has been involved with MIND in Carlisle for 16 years, and became President of MIND in 2001. His awareness of the distress that mental illness sufferers experience and of the stigma surrounding mental health has strengthened his 
resolve to campaign on mental health issues in the House of Lords, and to raise awareness of the extent of the problem.

\section{Dr Abraham Halpern}

Dr Halpern is a distinguished North American forensic psychiatrist. He began his career in Canada, but for many years he has worked in the USA. His CV includes a large number of important honours, including

Service Award, American Academy of Forensic Sciences, 1988

Honorary Life member, Canadian Academy of Psychiatry and the Law, 1994

Outstanding Humanitarian Award, Tri-State Chapter, American Academy of Psychiatry and the Law, 2000

Human Rights Award, American Psychiatric Association, 2000

President's Citizenship Award, Medical Society of the State of NewYork, 2003

Life Fellow, 1991-2003, Distinguished Life Fellow, 2003 American Psychiatric Association

He is best known to British psychiatrists for two things: he has been a very active member of the American Academy of Psychiatry and the Law, and was its President in 1982-1983. More significantly, and the reason for the recent honours, is his dedication to the cause of stopping doctors participating in the death penalty process, as they often do in the USA. Naturally, he is an abolitionist and he campaigns tirelessly, even now he is retired and troubled by heart disease, for these causes. He has sought and received Royal College support, and in spite of huge resistance to his message in America, he has made progress towards a policy ban on psychiatrist participation within the American Psychiatric Association.

Award of the Honorary Fellowship of the Royal College would be a just recognition and reward for his humanitarian work and give extra strength to $\mathrm{Dr}$ Halpern's campaign.

\section{Professor Philip Graham}

Professor Philip Graham is a child psychiatrist who, over the past 40 years, has had significant international influence. On the world scene, he has been a consultant to the World Health Organization (WHO) over a period of many years serving, among other roles, as a coordinating consultant for the WHO Child Mental Health programme from 1977 to 1984 . He served as president of the European Society of Child and Adolescent Psychiatry from 1987 to 1991 and held a part-time chair in child psychiatry at the University of Oslo from 1994 to 2000.
Throughout his career, Professor Graham has championed interdisciplinary collaboration, but his support has always been accompanied by a constructively critical approach to the problems and difficulties. Uniquely, he has twice been Chairman of the Association of Child and Adolescent Psychiatry - from 1982-1984 and currently from 2000. He was a member of the Warnock Committee of Enquiry on the Education of Handicapped Children (1974-1978) and played a major role in shaping its influential recommendations. For a decade (1976-1985), he was Consultant Adviser in Child Psychiatry to the Chief Medical Officer of the Department of Health, and during the next decade (1987-1994), he was a member of the Child Care Liaison Group at the Department of Health. He was a founding convenor of the Psychology and Psychiatry Special Interest Group of the British Paediatric Association (1984-85), and he chaired the Joint Working Party on Alcohol and the Young of the Royal College of Physicians and the British Paediatric Association (1993-95). Between 1994 and 2000, he was chairman of the National Children's Bureau and over the same period of time, he was a member of the Council of the London Institute of Education. He has played a major role in the Child Psychiatry section of the College, being a member of the executive committee from 1969-84, and serving as chair from 1974-77.

Professor Graham's academic and clinical achievements are outstanding and have been recognised around the world. He has a strong research record that began with the epidemiological studies on the Isle of Wight and then in Waltham Forest. The latter was especially important in its demonstration, for the first time, of the prognostic significance of psychopathology in the pre-school years, and its identification of crucial risk factors in individuals and in their families. He provided crucial leadership in building the NYS Department of Psychological Medicine at the Hospital for Sick Children at Great Ormond Street, and subsequently in establishing the academic department at the Institute of Child Health. His approach both in his clinical work and iresearch was strongly interdisciplinary and public health-orientated. He quickly earned the respect of paediatricians and this was reflected in his election to the Deanship of the Institute of Child Health in 1985.

As indicated by this selective description, Philip Graham has numerous achievements to his credit, any one of which might warrant election as an Honorary Fellow. However, most of all, he has been a superlatively good ambassador of psychiatry throughout the world and across a range of medical and nonmedical disciplines. Never afraid to tackle controversial issues, he is nevertheless an indefatigable worker for harmony and successful cooperative collaboration. His election as Honorary Fellow would be richly deserved.

\section{Professor}

\section{Genevra Richardson}

Professor Richardson is an academic lawyer with long-standing expertise in mental health law who has both a national and international reputation in the field. She is recognised as probably the most distinguished academic mental health lawyer in this country and has combined, over many years, her theoretical expertise with practical application. Hence, she was a member of the Mental Health Act Commission for some years and has chaired a major homicide inquiry. Her prominence was recognised by the Department of Health in its decision to appoint her as Chairperson of its own Scoping Committee on Mental Health Law Reform. This gave rise to a report, which was the only expert report that the Government relied upon in publishing its Green and White Papers and in subsequently producing its Draft Mental Health Bill. Her expertise and reputation have resulted in her being invited to spend time in other countries considering issues concerning law and mental health.

Professor Richardson's work has always been imbued with a deep understanding of the practical issues facing mental health users, carers and practitioners, and her recommendations to the Government on mental health law reform clearly reflected this. Since publication of the Government's Green Paper (followed by the White Paper and Draft Bill), Professor Richardson has remained an active and sought-after contributor to the debate about mental health law reform, often offering a robust critique of much that is proposed by the Government and which contradicts the recommendations of her own committee.

It would be difficult to find a lawyer more worthy of appointment to an Honorary Fellowship of our College. Nor could there be a more appropriate time than the present epoch in mental health care services and law to appoint someone of Professor Richardson's expertise and reputation to such an Honorary Fellowship. Professor Richardson is commended to the College in the highest terms.

\section{Election of President}

\section{Notice to Fellows and \\ Members}

Fellows and Members are reminded of their rights under the Bye-laws and Regulations, as follows: 


\section{Bye-law X}

The President shall be elected annually from among the Fellows.

\section{Regulation XI}

1. As soon as may be practicable after the first day of June in any year the Council shall hold a nomination meeting and shall at such meeting nominate not less than one candidate and not more than three candidates.

2. Between the first day of June in any year and the date which is four clear weeks after the nomination meeting of the Council, written nominations accompanied in each case by the nominee's written consent to stand for election, may be lodged with the Registrar, provided that each such nomination is supported in writing by not less than twelve Members of the College who are not members of the Council.

3. An election by ballot shall be held in accordance with the provisions of the Regulations.

The nominating meeting of the Council will be held on 27 January and the last date for receiving nominations under (2) above will therefore be 24 February.

Dr Mike Shooter is in his second year of office as President and is therefore eligible for re-election.

\section{Employment opportunities and psychiatric disability}

\section{Council Report CR111, \\ October 2002, Royal \\ College of Psychiatrists, f7.50, $124 \mathrm{pp}$.}

This report is aimed at people working in mental health services, but is of relevance to the wide array of agencies concerned with vocational rehabilitation.

Employment opportunities for people with mental illness are an important concern for those working in mental health services, not least because they form part of the rehabilitation and reintegration efforts associated with these services. However, the issues raised cut across many government departments and policy making bodies. Many agencies are concerned with employment opportunities for the disabled, thus making a large array of partnerships possible in this area.

Work and employment form a central part of most people's lives, including people with psychiatric disabilities, offering rewards beyond that of income. Work and meaningful activity give a sense of identity and other therapeutic benefits including increased self-esteem, enhancement of sense of worth and improved functioning. Regrettably, many people with mental illness are denied the opportunity to engage in these activities, despite their wish to. For those with severe mental illness the rates of unemployment are high, higher than for their fellow citizens with physical disabilities. Mental disorders are one of the three most common medical causes for being in receipt of Incapacity Benefit.

Employment is linked to social inclusion and is a crucial concern for those wishing to improve the fabric of society. Employment for those with mental illness gives opportunities for them to participate in society as active citizens, and the barriers to this are linked to stigma, prejudice and discrimination.

This report is focused on adults with psychiatric disorders. It is principally concerned with people with severe mental illness, but inevitably covers the problems of those with affective, anxiety, neurotic and other disorders who are at increased risk of absence from work and often find it difficult to get back into work if they are off sick for prolonged periods. While it is mainly concerned with secondary care services, general practice is given a prominent position. The general practitioner acts not only as a filter into secondary care, but also as filter into the welfare and employment arenas. Two matters concern people with psychiatric disabilities: getting into work and remaining in work. Employment opportunities and retention form the main focus of the report.

The report reviews the existing employment and vocational opportunities and the barriers to these for people with psychiatric disability; it considers the range of current employment and vocational schemes for people with psychiatric disability and their capacity to assist in retaining and regaining employment; and reviews the existing evidence for the need for employment and the effectiveness of schemes for those with psychiatric disabilities. Recommendations cover national policy, development of vocational services, psychiatrists and community mental health teams, primary care, training and education, commissioning, and research.

\section{The mental health of students in higher education}

Council Report CR112, January 2003, Royal College of Psychiatrists, f7.50, $66 \mathrm{pp}$.

The mental health of students in higher education has been highlighted in recent years because of a progressive increase in the number of students presenting to college counselling services, and in the apparent severity of their mental health problems.

Higher education institutions already make considerable provision for the wellbeing of their students. Most have sophisticated pastoral and counselling services in place, and there are numerous examples of good practice in identifying and supporting students with mental health problems

NHS facilities, both in primary care and specialist mental health services, also have a significant role to play in working with universities and colleges to address these needs. However, NHS mental health provision for students is variable, and there are sometimes obstacles to access and the continuity of care. Despite their intellectual abilities and potential for advancement, students with mental health problems are a disadvantaged population. The current modernisation of mental health services offers an opportunity to improve facilities for them.

The Royal College of Psychiatrists has investigated this complex subject, and its findings are contained in this report. Its aim is to review the nature, prevalence and causes of students' mental health problems, to review existing services, and to present recommendations for the development of strategic policy and best clinical practice. The recommendations will be of interest to students and higher education institutions, but are aimed primarily at those who commission and provide mental health services.

\section{Conclusions and recommendations}

1. The number of students presenting with symptoms of mental ill-health has increased in recent years, as has the number of students presenting with more severe mental health problems. Drug and alcohol misuse is a serious and growing concern.

2. Students report increased mental health symptoms compared with age-matched controls, but there is no evidence to confirm that students are more likely to suffer mental illness

3. Higher education is associated with significant stressors, including the emotional demands of transition from home and school to the less structured environment of college, independent study and examinations, and financial pressures. While stress is not pathological in itself, these factors may contribute to the higher rate of emotional symptomatology among students.

4. Mental health problems in students may be seriously disruptive to their education and emotional development.

5. Students in higher education are at no higher risk of suicide than the general population, and may be at lower risk. 


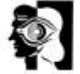

columns
6. The increased numbers of students seeking help with mental health problems may reflect:

- the increasing number of students entering higher education;

- the progressive approximation of the characteristics of the student population to the general population

- the increasing willingness of young people to seek help for a range of emotional and mental health problems.

7. University counselling services are the primary mental health care option for many students, and should be resourced accordingly.

8. Nationally agreed policies should be developed to ensure continuity of mental health care between the student's home area and the university, and to preclude conflicts between home and college NHS providers about funding.

9. Local networks should be developed to ensure shared policies and co-operation between colleges, primary care services, mental health services, and other relevant agencies.

\section{Psychiatric services to accident and emergency departments}

\section{Council Report CR118,}

January 2004, Royal

College of Psychiatrists,

f10, $96 \mathrm{pp}$.

This report supersedes the previous joint report (CR43) from the Royal College of Psychiatrists and the British Association for Accident and Emergency Medicine. Since the publication of the original report, new demands have been placed on both mental health services and $A \& E$ departments. The requirement that $90 \%$ of patients, rising to $100 \%$ in 2004 , must have been discharged from A\&E departments within 4 hours of arrival (Department of Health, 2001) will have a major impact on the interaction between mental health services and A\&E departments.

The main report examines the common mental health scenarios that occur in the A\&E department, issues affecting patients from ethnic minorities, specific problems in the A\&E department, personnel issues and the organisation of services.

The principal recommendations in this report are as follows:

\section{Summary of recommendations}

- There is a joint responsibility for commissioners, mental health service managers, and acute service managers to ensure that the input of mental health services to $A \& E$ departments is not overlooked in negotiations.
- A consultant psychiatrist should be named as the senior member of staff in the local mental health services responsible for liaison with the $A \& E$ department.

- A\&E department personnel should have adequate knowledge of mental health issues, and feel confident in making an initial assessment of people with mental health problems.

- Mental health problems should be included in the triage process.

- A\&E department staff training should include the recognition of common mental health problems, and the appropriate responses to that recognition.

- Mental health staff training should include training for A\&E department staff regarding what is helpful. Conversely, A\&E department staff require training from the mental health staff about what is practicable.

- Common training initiatives involving both staff groups address not only training issues, but also can lead to major operational benefits.

- Local policies should be agreed regarding common mental health problems that arise in the $A \& E$ department.

- The A\&E department should include facilities and resources for the assessment of patients with mental health problems. This should include an interview room with adequate safety features.

- Staff training should include safety issues.

- A Liaison Group, with representatives from the A\&E department and from mental health services, should review issues of joint working between the two services, establish joint working protocols, and ensure that the recommendations contained within this report are considered and implemented.

- The liaison group should be authorised by, and have agreed reporting structures to, the respectiveTrust boards.

\section{CPD audit policy}

The current Continuing Professional Development (CPD) policy of The Royal College of Psychiatrists, as laid out in Council Report 90 (Royal College of Psychiatrists, 2001), was introduced in April 2001. All the medical and surgical Royal Colleges and Faculties have implemented similar CPD policies. In an attempt to harmonise the approaches of the Royal Colleges, the Academy of Medical Royal Colleges introduced a CPD framework document (Academy of Medical Royal Colleges, 2002). This lists ten principles that all the Royal Colleges subscribe to. Principle six states, 'Colleges/faculties should fully audit a participant's activities on a random basis or whenever concerns about an individual's professional performance are raised. Such peer-based audit should verify the claimed activities have been undertaken and are appropriate. Participants will need to collect evidence to enable this process, normally using a structured portfolio cataloguing the different activities'. This is regarded as an important part of the quality assurance of CPD schemes.

\section{Obligatory aspects of the Royal College of Psychiatrists CPD scheme}

To be in 'good standing' for CPD, registrants with the College scheme have to:

(a) Prepare a personal development plan with a number of learning objectives to be met over the coming year or longer period.

(b) Discuss and agree the personal development plan in a peer group of two to eight doctors, most or all of whom should be psychiatrists.

(c) Review progress with the peer group at least once during the year.

(d) At the end of the year meet with the peer group and review whether learning objectives have been met.

(e) Complete Form E. This includes:

(i) The number of hours spent on internal CPD (i.e. local teaching meetings, case conferences, audit meetings, etc.) and external CPD (regional, national and international meetings) in the previous year. The total number of hours must be at least 50 .

(ii) A list of the members of the peer group with their College numbers.

(f) Verify the completed Form E in the peer group, where it is signed off.

(g) Return Form E to the College for validation.

(h) Begin the cycle again with a new personal development plan.

\section{Audit mechanism}

A random $5 \%$ of CPD registrants will be audited each year. This will commence in June 2004. Those randomly chosen will be informed shortly after the return of their Form E. The audit mechanism, which has been drawn up by the CPD Committee, has two elements:

(a) Registrants will be asked to provide some form of paper evidence relating to the external CPD meetings that they have attended in the previous year. Such evidence might consist of copies of the programmes of meetings attended, or alternatively certificates of attendance detailing the number of hours involved. The total number of hours should tally with the external CPD hours listed on Form E. 
(b) The member of the peer group who signed off the Form E will be approached separately for confirmation. He or she will be asked the following yes/no questions:

- Were the registrant's educational objectives properly discussed within the peer group?

- In your opinion was Form E completed correctly?

- Were the educational events attended appropriate to the registrant?

\section{CPD and appraisal}

Continuing professional development is part of the regulatory framework for career-grade doctors, i.e. doctors who are not in training grades (Bouch, 2003) Evidence of participation in continuing professional development is necessary for annual appraisal. When CPD registrants return their Form $E$ they will be issued with an annual certificate by the Royal College of Psychiatrists. For most members of the College these certificates will constitute the main evidence of satisfactory CPD for inclusion in appraisal/ revalidation folders.

The Royal College of Psychiatrists will not issue psychiatrists with a Certificate of Good Standing for CPD in the following circumstances:

- The psychiatrist is not registered for CPD.

- The CPD registrant does not complete or return a Form E.
- The CPD registrant returns a Form E that is unacceptable (e.g. peer group members not listed, insufficient number of hours, illegible, incomplete).

- The CPD registrant is audited and fails to meet the criteria specified above.

Such registrants will not be regarded by the College as being in good standing for CPD.

\section{Implications of not being in good standing for CPD}

Satisfactory participation in continuing professional development is essential for all career grade doctors. Psychiatrists who are not in good standing for CPD will not have evidence from the Royal College of Psychiatrists that can be included in the appraisal/revalidation folder. In this case it would be incumbent on the psychiatrist to assure the appraiser that the continuing professional development is appropriate and satisfactory. Possible mechanisms by which such assurance could be given might be:

(a) participation in another CPD programme - for example the Royal Australian and New Zealand College of Psychiatrists Maintenance of Professional Standards programme (the Royal College of Psychiatrists has a reciprocal arrangement with this College);

(b) at appraisal - the appraiser might look at the related paperwork of appraisees to ensure the individual has a personal development plan with appropriate learning objectives and appropriate participation in educational activities.

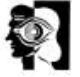

columns

\section{Conclusions}

Continuing professional development is essential for all career-grade doctors and as such will be a vital component of appraisal and revalidation. Participation in the Royal College of Psychiatrists CPD scheme is the means by which most career-grade psychiatrists will be able to provide evidence for these processes. Auditing the scheme is essential for the purposes of quality assurance, to harmonise with the other Royal Colleges and Faculties and to satisfy the General Medical Council that the College's CPD processes are robust.

\section{References}

ACADEMY OF MEDICAL ROYAL COLLEGES (2002) CPD: The Ten Principles. A Framework for Continuing Professional Development. London: Academy of Medical Royal Colleges.

BOUCH, J. (2003) (editorial) Continuing professional development for psychiatrists: CPD and regulation. Advances in Psychiatric Treatment, 9, 3-4.

ROYAL COLLEGE OF PSYCHIATRISTS (2001) Good Psychiatric Practice: CPD (CR90). London: Royal College of Psychiatrists.

Joe Bouch Consultant Psychiatrist and Director of CPD, Robert Jackson CPD and Postgraduate Education Officer, Royal College of Psychiatrists

\section{forthcoming events}

The North London Centre for Group

Therapy will be holding a group-analytic weekend workshop entitled 'Love and Power Bedroom to Boardroom' on 25-27 June 2004. The workshop will take place at The North London Centre for Group Therapy. Further details can be obtained from Lesley Holmes, The North London Centre for Group Therapy, 138 Bramley Road, Oakwood, London N14 4HU (tel: 0208440 1451; fax: 0208449 3847; e-mail: NLCent@aol.com).

The Pacific Rim College of Psychiatrists' XI Scientific Meeting will be held in Hong Kong on 28-31 October
2004. Interested parties should contact the Meeting Secretariat, c/o Meeting Planners International (HK) Ltd, 22/F, Pico Tower, 66 Gloucester Road, Wanchai, Hong Kong SAR (tel: +852 2509 3430; fax: +852 2667 6927; e-mail: PRCP@mphk.com).

Celebrating Women and Psychiatry: Inspiring Research, Teaching, Practice and Policy will be held on 29-30 April 2004 in Stoke-on-Trent. This conference is being organised by the Mental Health Research Group at Keele University to highlight high quality research achievements in British psychiatry by women, advances in understanding gender related issues, and innovations in practice and policy related to services for families. Seminars will be provided by a number of leading psychiatrists in their field on a broad range of topics aimed at mental health professionals, psychiatrists, psychologists, social workers, nurses, and general practitioners. For further information please contact Keele Facilities Management (tel: +(44)01782 584259; e-mail: j.deaville@kfm.keele.ac.uk) or visit their web site: http://www.keele.ac.uk/ depts/pc/conf.htm. 